\title{
TIPOS DE COMPORTAMENTO DOS EXTENSIONISTAS NA EMATER-GO
}

\section{ALIPIO CORREIA FILHO}

Orientador: JOSE MOLINA FILHO

Dissertação apresentada à Escola Superior de Agricultura "Luiz de Queiroz", da Universidade de São Paulo, para obtenção do título de Mestre em Agronomia. Área de coricentração: Sociologia Rural.

PIRACICABA

Estado de São Paulo - Brasil Janeiro, 1983 
Aos que lutam pelo homem do campo, aos extensionistas locais da EMATER-GO. 


\section{AGRADECIMENTOS}

O esforço acadêmico de elaboração e conclusão de uma dissertação de MS longe está de ser uma tarefa puramen te individual. A nossa experiência na ESALQ/USP nos mostrou que tambêm na Universidade o processo de criação e desenvolvi mento de idêias de pesquisa è essencialmente um processo cole tivo, onde se torna difícil a imposição de limites entre o que se origina do estudante e o que vem como contribuição dos professores e dos outros colegas pós-graduados. No esforço coletivo desta dissertação alguns professores e colegas foram de importância crucial. Daí fazermos questão de tornar explí cito os nossos agradecimentos:

- ao Dr. Josê Molina Filho, mestre, amigo, or $\underline{i}$ entador;

- ao colega - amigo - irmão Sêrgio Penna, pela ajuda em todas as fases do trabalho, pelos ensinamentos, pela competência em corrigir, 
pelo denodo;

- ao Dr. Wenceslau J. Goedert, pelo exemplo e incentivo;

- ao Dr. Luis Hernan Rodriguez Castro, pelos ensinamentos e anālises estatísticas.

- aos Doutores Elmar Wagner, Delmar Marchetti e Edson Lobato, pelo apoio moral e suporte institucional;

- A Empresa Brasileira de Pesquisa Agropecuă ria-EMBRAPA, pela oportunidade, incentivo e amparo financeiro;

- à Empresa de Assistência Técnica e Extensão Rural de Goiás, na pessoa do seu presidente, Dr. Vicente Benjamin de Albuquerque;

- ao Departamento de Economia e Sociologia Ru ral da ESALQ/USP, nas pessoas do Dr. Joaquim Engler, dos professores e demais funcioná rios;

- ao Departamento de Informação e Documentação da EMBRAPA, na pessoa do seu Chefe Dr. Ubal dino Dantas Machado;

- aos colegas de mestrądo, pelo afeto e apoio.

- à biblioteca da EMBRAPA-Sede, pelo apoio e prestimosidade, nas pessoas de Maria José de 
Oliveira, Marlene de'Souza Costa e José Eus táquio Ferreira.

- à Massae Tada, que datilografou com carinho as ültimas versões deste trabalho. 


\section{INDICE}

Pāgina

Lista das Tabelas ................................. vi

Lista dos Quadros ...................... viii

Lista das Figuras ....................... ix

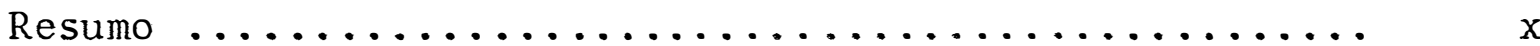

Summary ........................................

Capítulo I - O Problema e Sua Importância ......... 1

Capítulo II - Orientação Teórica ................ 13

1. Quadro Teórico de Referência ....... 13

2. Aplicação Empírica do Referencial Teórico .................... 23

3. Técnica de Anālise .............. 25

Capítulo II - Estratégia da Pesquisa ............ 28

1. População e Area Estudadas ........ 29

2. Instrumento de Coleta dos Dados .... 32

Capítulo IV - Análise dos Resultados ............. 3ذ

Capítulo V - Conclusões ................ 54

Bibliografia $\ldots \ldots \ldots \ldots \ldots \ldots \ldots \ldots \ldots \ldots \ldots \ldots \ldots \ldots \ldots \ldots \ldots$ 
vii

\section{LISTA DAS TABELAS}

Pāgina

1 - Mëdia das Variāveis nos Diferentes "Clusters"..... 37

2 - Distribuição dos Extensionistas em cinco "clusters" 40

3 - Comparação da Classificação dos Extensionistas de Acordo com a Análise de "cluster" com a dos Super visores Regionais (juizes) ................. 43

4 - Mẻdia das Variáveis nos Diferentes Tipos de Comportamento $\ldots \ldots \ldots \ldots \ldots \ldots \ldots \ldots \ldots \ldots \ldots \ldots \ldots \ldots, 45$ 
1 - Tipologia de Modos de Adaptação Individual ........ 16

2 - Tipologia dos Modos de Adaptação do Agentes de Extensão. EMATER-GO 1978.......................... 24

3 - Total de Técnicas por Cargos. EMATER-GO 1979..... 30

4 - Classificação dos Indivíduos da Amostra Feita pelos Juízes e Pela Análise de "Cluster" ......... 42 


\section{LISTA DAS FIGURAS}

1 - Locais Visitados Pelos Entrevistadores. Estado de

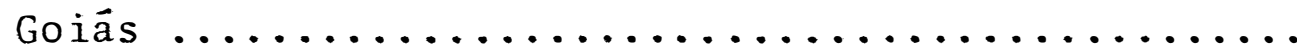




\section{RESUMO}

Esta dissertação envolveu o estudo explorató rio-descritivo dos tipos de comportamento dos extensionistas da Empresa de Assistência Tëcnica e Extensão Rural do Estado de Goiás (EMATER-GO). O problema bảsico foi formulado atra vês da pergunta: quais são os tipos característicos de adaptạ ção dos agentes de extensão da EMATER-GO? A resposta para es ta questão-problema foi buscada em forma de tendência. Isto é, se no momento "t" - o momento da pesquisa - a distribuição dos extensionistas era " $x$ ", quais as tendências de mudança dessa distribuição no momento " $t+1 "$ ?

Quatro objetivos básicos nortearam o trabalho: (1) categorizar empiricamente as unidades de análise de acor do com determinados tipos de comportamento adaptativos; verificar se as formas adaptativas de comportamento estavam em conformidade com os padrões de organização e funcionamento da EMATER-GO; (3) procurar estabelecer as tendências de con 
centração dos diferentes tipos de adaptação; e (4) oferecer sugestões à EMATER-GO em termos de reestruturação do comporta. mento dos agentes de extensão, de tal forma que a probabilida de deles, se adaptarem de forma construtiva aos princípios da Empresa, seja aumentada.

Ficou evidenciado, como a própria anālise fun cionalista sugere, a "acomodação" dos elementos "estranhos" ao sistema pelo próprio sistema. A tendência foi para se ob ter, dos cinco grupos de comportamento divergentes iniciais, dois grandes grupos no final. Um, composto por 9 extensionis tas e o outro, constituído por 28 extensionistas. 
SUMMARY

An exploratory-descriptive study of the different types of behavior of extension agents working for the Empresa de Assistência Técnica e Extensão Rural do Estado de Goiás (EMATER-GO). The basic research problem involved the question: what are the typical forms of adaptation shown by the extension agents of EMATER-GO? The answer was sought in the form of a tendency, i.e., if in a " $t$ " moment - the research moment - the distribution of the extension agents was " $x$ ", what are the tendencies for changes of this distribution in the moment $t+1 "$ ?

This work was guide by four basic objectives:

1) To classify empirically the unit of analysis in accordance with specific types of adaptive behaviors;

2) To verify if the adaptive forms of behaviors were in accordance with the patterns of organization and functioning of the EMATER-GO; 
3) To try to determine the concentration tendencies of the different types of adaptation;

4) To provide suggestions to EMATER-GO in terms of reorienting the behavior of the extension agents so as to increase the probability of a better adjustment to the principles established by the organization.

Evidence strongly suggests an "accomodation"

of the elements "foreign" to the system by the system itself as suggested by functionalist analysis. There was a tendency toward the formation of two large groups, from the initial five groups of divergent behavior, one including nine extension agents and a second including 28. 


\section{CAPITULO I \\ O PROBLEMA E SUA IMPORTÂNCIA}

A Empresa de Assistência Técnica e Extensão Ru ral do Estado de Goiás (EMATER-GO), associada ao Sistema Bra sileiro de Assistência Técnica e Extensão Rural (SIBRATER), é uma organização (1) que visa, basicamente, o aumento da produ tividade e produção agrícolas, assegurando melhores níveis de renda e de vida para o produtor rural (2). Esses objetivos, os quais são gerais a todo o SIBRATER, devem ser alcançados através da ação de transferência de tecnologia agronômica e gerencial, assim como de conhecimentos e habilidades de natu reza social, econômica e política. Dessa forma, é esperado dos extensionistas locais(3) - os quais formam a linha de frente da organização - o desempenho dos seus papéis de trans ferência de tecnologia, com vistas às finalidades de todo o sistema. Em outras palavras, devem repassar aos produtores, criticamente, os conhecimentos e técnicas desenvolvidas pela 
pesquisa agropecuāria, visando ao aumento da produção, da produtividade e da renda. Os extensionistas locais devem tra balhar junto aos produtores para que eles se mobilizem com vistas à organização da sua categoria, nas vârias formas de ajuda mútua, de cooperação e de sindicalização; devem educar as familias e as comunidades para que melhorem sua qualidade de vida, utilizando os recursos adicionais provenientes do au mento da renda e da mobilização social.

A expectativa com relação à ação do extensio nista é, pois, muito variada e ampla, envolvendo uma série de atividades, muitas das quais extrapolam a sua formação e ex periência profissionais. Nesse sentido, se supomos como atrí buições específicas dos extensionistas a transferência de tec nologias agropecuāria e gerencial objetivando aumentos da pro dução, produtividade e da renda, é de se esperar a ocorrência de certas discrepâncias entre o que a organização espera des ses extensionistas e o que eles vêm efetivamente realizando. 0 entendimento da extensão rural, da expectativa que as empre sas de extensão possuem em relação aos seus extensionistas, liga-se muito às suas origens e à sua história. Mas quais são os primórdios da extensão rural e como ocorre o aparecimento da ACAR-GO?

A história da extensão rural no Brasil começa com a criação dos "Trabalhos Cooperativos" no município pau lista de Santa Rita do Passa Quatro. Isto aconteceu em 1948, 
sob o patrocínio de agricultores, industriais, prefeitura e governo do Estado de São Paulo, quando um grupo de técnicos orientados pela "American International Association"

(AIA) deu início à primeira experiência sistemática de um serviço de extensão rural no Brasil. Essa primeira experiência não alcançou o êxito esperado, mas, mesmo assim, o Estado de Mi nas Gerais e a AIA, no dia 6 de dezembro de 1948, criaram o primeiro serviço estadual de extensão: a Associação de Crédi to e Assistência Rural de Minas Gerais (ACAR). Ao iniciar suas atividades, a ACAR dispunha de objetivos e metodologias à imagem e semelhança dos serviços de extensão rural dos Esta dos Unidos, pois copiara seu modelo do "Cooperative Extension Service" e da "Farmer's Home Administration". Com o passar dos anos, outras Associações de Crédito e Assistência Rural (ACAR) foram criadas pelos estados e, a 3 de março de 1959, foi implantada a Associação de Crêdito e Assistência Rural do Estado de Goiās (ACAR-GO), seguindo as mesmas diretrizes da Associação Brasileira de Crédito e Assistência Rural (ABCAR) . O sistema ACAR-GO sobreviveu até novembro de 1974, quando o Governo Federal criou a Empresa Brasileira de Assistência Téc nica e Extensão Rural (EMBRATER) com a atribuição de coorde nar o Sistema Brasileiro de Assistência Técnica e Extensão Ru ral (SIBRATER). Em outubro de 1975 foi criada a Empresa de Assistência Técnica e Extensão Rural de Goiās (EMATER-G0) que teve sua consolidação a partir de janeiro de 1977. A antiga ACAR-GO transformou-se, assim, na EMATER-GO. 
Este histörico vem marcado pela persistência dos objetivos propugnados que se resumem: "... sempre visando o aumento da produção e produtividade agropecuária e a eleva ção da renda do produtor rural, com consequente melhoria do seu nivel de vida" (PROATER-GO 1979). Ora, se a histöria da extensão estã marcada pela imprecisão dos seus objetivos (Cam pelo 1973, como então poderíamos analisar o comportamen to dos extensionistas?

Estudos realizados por Mata (1978) apontam o extensionista como um técnico de percepção 1 imitada, da forma como ocorre o relacionamento entre setores da economia nacio nal e com explicações da não adoção das técnicas recomendadas por eles, com base na racionalidade empresarial do produtor. Ainda, no sentido da busca de explicações para o comportamento dos extensionistas, vários. outros estudos empíricos versavam sobre as disfunções existentes entre o comportamento dos ex tensionistas e aqueles esperados pela organização a que se vinculam destacando-se entre outros: Ramos (1973), Lopes (1976) e Machado Filho (1973). Este último caracterizou. o desempe nho funcional dos extensionistas, como atributos do estágio de desenvolvimento em que se encontram as organizações de ex tensão rura1.

Fonseça (1973) também compreende que ao exten sionista são imputadas responsabilidades que normalmente fo gem à sua alçada, e dicotomiza as ações destes em: (a) ação extensionista de assistência técnica e (b) ação de promoção 
humana. A ação de promoção junto às famílias rurais é catego rizada em quatro tipos: a) ação iniciadora, que requer do ex tensionista características de inovador; b) ação catalisado ra, que requer do extensionista uma efetiva liderança na comu nidade; c) ação aceleradora, que exige do extensionista ele vado grau de percepção política institucional e dinamismo e; d) ação multiplicadora, que requer do extensionista bom conhe cimento de Psicologla Social e Educação. A essas responsabị lidades exacerbadas somavam-se intangiveis objetivos histori camente aceitos e repetidos pelos serviços de Extensão.

Pinto (1972) traz uma nova visão do extensio nista. Procura enfocá-lo na totalidade da sua estrutura, co locando-o nas dimensões de ator, sob as perspectivas de suas referências com o processo de integração social. Para Pinto (1972), o extensionista não é um ser abstrato que atua isola damente na sua comunidade, ele tem o significado do ser huma no na posição estrutural de classe, com papéis definidos pela sua prätica social e é portador de uma ideologia. Baseando-se nessa pressuposição, considerando o extensionista como um elemento de ligação entre o fato tecnológico e os ambientes social e organizacional, este trabalho procura descobrir as formas (tipos) de adaptação do indivíduo à organização.

Os autores, até aqui citados, dão conta da im portância que a organização estruturada e definida tem na qua lidade dos trabalhos dos seus técnicos. O que vimos foi que 
o tipo de atividade, desenvolvida pelos extensionistas, não se 1 imita ao plano do produtor ou mesmo das condições ambien tais para o desempenho de suas atividades, mas, antes, rela ciona-se com as proposições da organização a que estejam vin culadas suas atividades profissionais.

A EMATER-GO, como organização, e os seus

extensionistas como elementos responsáveis pela execução dos programas de trabalho, serão os objetos desta pesquisa. A anâlise da ação extensionista, necessariamente, baseia-se na caracterização do profissional enquanto ator, na concepção do sistema geral da ação (Parsons 1974). Implica em estudar o sistema social e a ação integradora que o ator co extensionis ta) desempenha. O ator para Parsons è um ser dentro de uma situação e que reage a sinais dentro do seu ambiente.

A compreensão da interação social se dá na perspectiva da anâlise sistêmica da ação humana. A teoria parsoniana legitima as características de sistema a toda ação, dando-1he estruturas e processos bem definidos, corresponden tes às abordagens de sistemas dadas a outras ciências. A per cepção do sistema de ação tem início a partir do momento em que haja uma organização, delineando-se: uma estrutura que con tenha elementos relativamente estáveis e que sirvam como referência para a análise do sistema; uma função, na medida que satisfaça certas necessidades do sistema e um processo evolutivo regido por certas regras e padrões. O sistema so 
cial ou sistema de interação humana, assim concebido por Par sons, empresta a este trabalho a fundamentação funcionalista da ação extensionista.

As valorações culturalmente estabelecidas so bre o desempenho funcional de uma organização não podem ser compreendidas a partir dos índices técnicos estabelecidos ou alcançados; pelo contrário, a integração de papéis de indiví duos-atores é que propicia a análise da funcionalidade da or ganização. Estabelece-se um paradoxo na avaliação da organi zação. A primeira noção de avaliação é a de que a ação coe citiva das organizações define os papéis, atribuições, normas e valorações das metas. A segunda, se afigura no contexto do sistema de ação, na busca dos graus de integração entre indi víduos e entre estes e a instituição.

Este trabalho estudará o sistema de ação dos indivíduos da organização (os extensionistas) em um aspecto bastante específico, isto é, o que se procura entender é aque le sistema de ação possível de ser classificado em diferentes formas de adaptação à organização. E importante ressaltar que, embora se reconheça a existência da ação coercitiva da organização na definição de papëis, atribuições, normas e va loração das metas, não se procurará medir ou controlar este tipo de ação.

Do ponto de vista teórico da análise funcio nal, Merton (1968) explica os comportamentos socialmente di 
vergentes ou conformistas aos objetivos e normas da organiza ção, como produto da estrutura social. São descartados, para efeito de anālise sociológica, as variāveis da personalidade patológica encontradas em grupos. Didaticamente, pode-se de $\underline{s}$ tacar dois elementos analíticos separáveis, mas que se mistú ram em situações concretas. Os objetivos culturalmente defí nidos e as normas para alcançar esses objetivos. 0 atingimen to de objetivos culturais estão invariavelmente ligados a re gulamentos.

Nos contatos preliminares realizados com os ex tensionistas para o planejamento desta pesquisa foram verif $\underline{i}$ cados casos que podem ser tipificados como o que segue: o Cen tro de Pesquisa Agropecuâria dos Cerrados (CPAC) desenvolveu novas técnicas para a adubação corretiva ${ }^{(4)}$ para recuperação dos solos dos cerrados do Brasil central. Essa tecnologia, entendida como tecnicamente recomendäve1, economicamente jus tificável e socialmente desejável, se constitui num conjunto de präticas relativamente fáceis e adequadas ao público de produtores da região. Os extensionistas da EMATER-GO foram treinados formal e informalmente sobre esse novo "pacote de adubação". Além disso, receberam publicações diversas sobre a matêria e contavam com a cobertura técnica dos especialis tas do CPAC. No entanto, foi observado que muito dos exten sionistas não utilizaram essas práticas em suas próprias un $\underline{i}$ dades produtivas (alguns dos extensionistas são também pro prietārios rurais) nem as difundiram entre os demais produto 
res. Como este não é um caso isolado, mas de recorrência fre quente entre os membros do serviço oficial de extensão do Es tado de Goiás, o estudo sobre os tipos de adaptação desses ex tensionistas à EMATER-GO se apresenta como um passo importan te para o entendimento da ação extensionista naquele Estado.

0 problema básico deste trabalho pode então ser formulado da seguinte maneira: quais são os tipos de adap tação característicos dos agentes de extensão da EMATER-GO ? Devido ao nível exploratório do trabalho, a busca de resposta para este problema se dará ao nível descritivo de abordagem, isto é, não existe aqui nenhuma intenção de se criar ou de se verificar leis e conclusões que se apliquem além da amostra e dos indivíduos trabalhadores. A intenção e limites deste es tudo são o de oferecer idéias e direções para outros poss $\underline{i}$ veis estudos. A resposta para a questão-problema, acima colo cada, deve ser buscada em forma de tendência. Se no momento "t" - o momento da pesquisa - a distribuição dos extensio nistas era " $x$ ", quais as tendências de mudança dessa distr $\underline{i}$ buição no momento " $t+1 "$, por exemplo?

$\underline{\text { Objetivos }}$

São quatro os objetivos deste trabalho. 0 pri meiro deles é o de categorizar empiricamente as unidades de anālise, isto é, os extensionistas da EMATER-GO, de acordo com determinados tipos de comportamento adaptativos. 0 segun do objetivo é o de verificar se as formas adaptativas de com 
portamento estão em conformidade com os padrões de organiza ção e funcionamento da EMATER-GO. O terceiro objetivo é o de procurar estabelecer as tendências de concentração dos dife rentes tipos de adaptação. O último objetivo ê o de dar su gestões à EMATER-GO em termos de reestruturar o comportamento dos agentes de extensão, de tal forma que aumente a probabili dade deles se adaptarem de forma construtiva aos princípios da empresa. 
NOTAS DO CAPITULO I

(1) o conceito de organização que estamos utilizando aqui é si nônimo de associação e, portanto, diferente do conceito dé organização social que se refere ao conjunto de todas as ações sociais realizadas numa determinada sociedade. Orga nização ou associação é também diferente de instituição . Quando nos referimos à EMATER-GO selecionamos o seu aspec to associativo; quando o fazemos com relação a um sistema de pesquisa ou a um sistema de extensão nos fixamos em seus aspectos institucionais. Sociologicamente, uma institui ção não se confunde com um indivíd'lo ou um grupo. "Uma in $\bar{s}$ tituição é uma configuração ou combinação de padrões de comportamento compartilhados por uma coletividade e centra dos na satisfação de algumas necessidades básicas do grū po" (Fichter. 1967). A combinação de padrões de com portamento que fazem do pesquisador agrícola um cientistā ou um tecnólogo compōem uma instituição social. Dessa for ma, uma instituição são asformas ou condições de comportā mento estabelecidas que caracterizam a atividade do grupo (veja-se, por exemplo, Maclver \& Page 1960). A combina ção de individuos podem formar associações (grupos secundă rios) mas não uma instituição. Uma organização é pensadā aqui em termos de atividade concreta. Firth (1966) co loca a idéia de organização como a de "pessoal obtendo coi sas por uma ação planejada", ou seja, como a "união de di versos elementos numa relação comum". Neste sentido é que entendemos a EMATER-GO como uma organização, e é dentro des te contexto que falamos em proposições organizacionais da EMATER-GO.

(2) o Programa de Assistência Técnica e Extensão Rural do Esta do de Goiás (PROATER-GO) e o Relatório de Atividades, a⿳亠m bos de 1979 e da EMATER-GO, dizem que a organização visa $\overline{0}$ aumento da produção e da produtividade da agropecuária, me lhoria da renda e do nível de vida do produtor rural.Acre $\bar{s}$ centa que esses objetivos devem ser alcançados através dé orientações agropecuárias, econômicas e sociais.

(3) O Extensionista Local é o profissional de nível médio ou superior, habilitado nas áreas agronômicas ou zootécnicas, que atua diretamente com os produtores rurais. E, na verdade, o vínculo existente entre a organização de Assis tência Técnica e Extensão Rural e o produtor. 
(4) Adubação corretiva é a elevação do nível de fertilidade do solo, de uma só vez, para um patamar que se baseia no con ceito de máxima eficiência econômica. Se por exemplo, um solo apresenta de zero a cinco ppm de $\mathrm{P}$ recomenda-se adi cionar $240 \mathrm{~kg}$ de $\mathrm{P}_{2} \mathrm{O}$ por hectare, para elevar a fertilida de, de uma só vez, para níveis em torno de 9 ppm de P. $\bar{A}$ lém do valor do elemento $P$ o elemento $K$ deve ser observado para que seu valor no solo não seja inferior a $48 \mathrm{ppm}$, que a saturação de $\mathrm{Al}^{+++}$maior que $20 \%$, ou o teor de Cálcio e Magnésio inferior a 2 meg., sejam corrigidos com calagem e por fim que seja observada a presença do Enxofre e de Mi cronutrientes. 


\section{CAPITULO I I}

\section{ORIENTACGAO TEORICA}

Há neste capítulo o desenvolvimento dos elemen tos teóricos utilizados na anālise dos dados. E importante deixar explícito que ao invés de se tentar um desenvolvimento teórico para explicar um fenômeno empírico, hả uma ênfase so bre a operacionalização do quadro teórico em função do proble ma proposto. Porquanto, dar-se-á mais ênfase sobre um quadro teórico de referência e as limitações do estudo decorrentes normalmente da própria aplicação empírica daquele refereñcial teórico. Além disto, há uma explicitação do instrumental ma temático utilizado no estudo, sobretudo a sua adequação à teo ria e problema a ser investigado.

1. Quadro teórico de Referểncia

o enfoque teórico deste estudo é fundamentado na proposição de Merton (1968) sobre os tipos de adaptação 
individual. Einteressante ressaltar que esta perspectiva teórica é geral, não se consubstanciando em um instrumento analítico para categorizar uma realidade empírica imediata. Isto é, as metas culturais e os meios institucionalizados, os quais se constituem em conceitos importantes para a classifí caçao dos tipos de adaptação, são necessários, mas não suficí entes para o mesmo fim.

Deste modo, hã a possibilidade de adequação desse instrumental teórico quando uma realidade é especifica da; onde esta adequação passa a ser determinada pelas próprias características do elemento a ser investigado. Como o objeto de estudo é a EMATER-GO, instituição de assistência técnica, a qual será analisada através dos seus técnicos cos agentes de extensão), não se empregará a terminologia mertoniana, ape sar do problema ser enfatizado em termos de classificação dos agentes de extensão.

O importante é que a pressuposição teórica de Merton é aqui assumida, isto é, "... a estrutura social opera a fim de exercer pressões sobre os indivíduos" (213). Não há um interesse em analisar quais os elementos estruturais que determinam essas "pressões" bem como qual a sua intensidade. E fundamental para este estudo que os agentes de extensão, a través de algumas características pessoais e perceptivas em relação à organização, possam ser diferentemente classifica dos. 
Apenas para entender melhor esses aspectos é interessante deixar explícito qual é a preocupação bãsica de Merton. Este autor está preocupado com o estudo da estrutura social, do ponto de vista da anälise funcional. Sob este en foque, o comportamento social é divergente devido a estrutura social, e a funcionalidade/disfuncionalidade dessa estrutura é determinada pela não-identificação/identificação do compor tamento socialmente divergente. Como o próprio Merton advoga, os termos funcionais/disfuncionais são imprecisos. Não ob $\underline{s}$ tante, no contexto da EMATER-GO, admite-se que a funcionalida de dos tipos adaptativos seria focalizada em termos de confor midade. Apesar de Merton enfatizar a necessidade de se pes quisar os processos de mudanças básicas na estrutura social, a anālise aqui desenvolvida não contempla este aspecto. Dian te disto, pode-se, desde já,identificar uma das limitações do presente trabalho: a sua categorização estática. Apenas para ilustrar este aspecto, a Tabela 1, mostra os tipos de adapta ção individual sugeridas por MERTON. (1968).

No Quadro 1 o sinal (+) significa "aceitação" e o sinal (-) significa "rejeição", enquanto que os sinais $( \pm)$ significam "rejeição" de valores predominantes e sua subs tituição por novos valores. E importante destacar que o Qua dro 1 reflete as proposições teóricas desenvolvidas por Mer ton. Dentro desta perspectiva, os modos de adaptação estão assim definidos: Conformidade, indica o comportamento orienta do para valores básicos, padrões culturais estabelecidos, da 
Quadro 1. Tipologia de Modos de Adaptação Individual

\begin{tabular}{lcc}
\hline Modos de adaptação & Metas culturais & $\begin{array}{c}\text { Meios } \\
\text { instịtucionalizados }\end{array}$ \\
\hline Conformidade & + & + \\
Inovação & + & - \\
Ritualismo & - & + \\
Retraimento & - & + \\
Rebelião & + & +
\end{tabular}

Fonte: Merton (1968)

sociedade. Este tipo de acomodação refletiria uma sociedade estável. Inovação, enfatiza a utilização de meios institucio nais, que apesar de serem "socialmente" proibidos, se constí tuem em mecanismo eficientes na obtenção das metas culturais. o sinal menos, atribuído a este tipo de adaptação, revela uma consequente rejeição dos instrumentos socialmente institucio nalizados. Ritualismo, se caracteriza pela rejeição às metas culturais. Isto indica que o comportamento é institucional mente permissível, podendo não ser "aquele" socialmente espe rado. A expressão mais comum do ritualista seria "... que as ambições convidam à frustação e ao perigo, ao passo que as as pirações mais baixas produzem satisfação e segurança", (Me ton 1968). Esta forma de adaptação não é conformista, nos moldes anteriormente definidos. Ela poderia ser identifi cada como conformista aos costumes. Retraimento 2 implica na rejeição das metas culturais e dos meios institucionalizados. 
Este tipo de adaptação é totalmente diferente dos demais. 0 indivíduo é um frustrado, não compartilha dos mesmos valores com os demais, sendo considerado sempre "estranho" para os de mais. "O derrotismo, quietismo, e a resignação são manifes tos em mecanismos de fuga que, posteriormente, o levam a fugir dos requisitos da sociedade" (Merton 1968). opõem-se à metas culturais e meios institucionalizados, procu rando por uma estrutura social diferente, a qual pessa substí tuir a anterior. Este modo de adaptação é usualmente contra os elementos legitimados do sistema. "Ela pressupõe o afasta mento dos objetivos dominantes, e dos padrões vigentes, os quais vem a ser considerados como puramente arbiträrios" (Me ton 1968 ).

Essas definições teóricas são derivadas em ter mos das metas culturais e dos meios institucionalizados. Con siderando-se que o estudo aqui desenvolvido não emprega aque les parâmetros, torna-se necessārio fazer outras especifica ções no modelo proposto por Merton. Mais particularmente, considerar-se-ā um conjunto de variáveis que refletem algumas características das tendências dos comportamentos dos agentes de extensão bem como as suas percepções sobre a organização em que trabalham. Assim sendo, os modos de adaptação serão em função, ünica e exclusivamente, dessas variāveis, não se especificando a priori nenhum direcionamento aos possiveis es cores que cada agente de extensão obterá em cada tipo de adap tação. Diferente de Merton, o qual atribui sinais na sua ti 
pologia de modos de adaptação individual, neste estudo não se formularā situações hipotêticas para aqueles diferentes tipos de adaptação. Por conseguinte, este estudo poderâ contribuir para identificar quais as variáveis que compõem os tipos de adaptação bem como os escores obtidos pelos agentes em cada una dessas variāveis.

Com relação a essas variáveis é importante que se esclareça que elas não foram diretamente derivadas da teo ria mertoniana, mas decorrentes do próprio contexto analitico de Merton. O caráter a-teórico das variāveis aqui seleciona das justifica-se pela própria natureza empírica descritiva des te estudo. Há uma tentativa de identificar aspectos estrita mente selecionados aos agentes de extensão e a organização em que eles trabalham.

E oportuno lembrar aqui que no desenvolvimento de sua teoria Merton não apresenta uma justificativa para a inclusão de metas culturais e meios institucionalizados como parâmetros para a identificação dos modos de adaptação. Alêm disso, é bom que se explicite que a própria natureza da teo ria social fornece elementos ambiguos na identificação das va riāveis e o próprio Merton, atravēs das proposições em favor da teoria de médio alcance, faz algumas ponderações neste sen tido. Deste modo, se a ausência de uma teoria limita, em cer tos aspectos, este trabalho, a tentativa aqui desenvolvida não é inócua no seu todo. Ela faz sentido em função da natu reza da problemática analisada. Desta forma, as variāveis $\underline{u}$ 
tilizadas neste estudo estão assim definidas e operacionalizą das :

1. Experiência profissional: esta experiência diz respeito apenas à EMATER-GO como organização. Não se con siderou a experiência em outras organizações pelo fato da EMATER-GO ser o elemento de referência para este estudo. Es ta variável foi operacionalizada em termos de anos de traba 1 ho.

2. Formação profissional: o conteúdo desta va riāvel expressa a formação formal do agente de extensão, a qual foi medida através de quatro indicadores: a) a existên cia de disciplina de extensão rural no histórico escolar; b) a participação em estágios em escritórios da ATER; c) a espon taneidade na opção do curso de agronomia; e d) a espontaneida de na opção para a função de extensionista. Cada indicador recebeu os valores de zero a três. Zero, em caso de não res posta, 1 , em caso de resposta negativa, 2 , em caso de resposta intermediāria e 3 , em caso de resposta positiva. Deste modo, o escore obtido por cada agente de extensão nesta variável constituiu-se do somatório dos diferentes indicadores.

3. Apoio institucional: esta variável reflete a percepção que o agente de extensão tem sobre a empresa em termos de alguns aspectos institucionais. Esses aspectos são: recebimento de assessoramento técnico, existência de manuais técnicos fornecidos pela empresa, patrocínio de cursos de 
atualização pela empresa, existência de infra-estrutura ade quada para o desempenho das atividades de extensão e reforço por parte da instituição, da filosofia de trabalho e dos prin cípios extensionistas. Cada indicador recebeu valores de ze ro a três, e o escore final constituiu-se do somatório desses valores.

4. Atualização profissional: esta atualização diz respeito às informações oriundas de publicações técnicas na área de extensão rural. Para operacionalizar esta variáa vel, os seguintes indicadores foram utilizados: recebimento de publicações na ārea de extensão rural, se estas publica ções são especializadas no tratamento das questões tecnológ cas, se as publicações são lidas sistematicamente, se o agen te de extensão solicita esclarecimento sobre os resultados das pesquisas e se hâ o hábito de ler essas publicações. Cá da indicador assumiu valores de zero a três, e o escore final atribuído constituiu-se do somatório dos valores individuais.

5. Participação na comunidade: o conteủdo espe cífico desta variável é a participação do agente de extensão nos diferentes grupos formal e informal, bem como se há algum conflito entre ele e outros elementos da comunidade. Esta va riâvel é medida através dos seguintes indicadores: participạ ção em cooperativa, congregação religiosa, clube de futebol etc, existência ou não de conflitos com os elementos de um mo do geral e intenção de continuar morando no local. Cada indi cador recebeu valores de zero a três. O escore atribuído re 
sultou do somatório dos indicadores.

6. Percepção sobre a pesquisa: considerando que o extensionista trabalha com os resultados imediatos da pesquisa em geral, tenta-se,através desta variāvel, apreender qual a sua opinião sobre a viabilidade daquelas recomendações em função da sua própria experiência em relação aos problemas que envolvem o produtor rural. Para tanto, selecionou-se os seguintes indicadores: a) conhecimento ou não, da dinâmica de uma instituição de pesquisa; b) opinião sobre a habilidade dos pesquisadores em gerar novos conhecimentos; e c) se essas inovações estão ou não resolvendo os problemas dos produtores. Houve a atribuição de escores de zero a três a esses indicado res, os quais foram somados posteriormente.

\section{Percepção sobre a tecnologia recomendada:}

esta variāve1. è uma complementação da anterior. Isto é, en quanto aquela enfatiza a pesquisa em si, esta diz respeito ao resultado específico da pesquisa. Isto. é, a tecnologia. Ou seja, nesta variável pretende-se identificar a opinião do ex tensionista sobre tecnologias, se os produtores podem "con fiar" nelas como alternativas para os problemas de produtivi dade rural. Esta variável foi operacionalizada através dos seguintes indicadores: a) confiabilidade ou não nos resulta dos da pesquisa; b) confiabilidade ou não atribuída aos paco tes tecnológicos; e c) opinião sobre a tecnologia como instru mento suficiente para o aumento da produtividade. Cada item 
recebeu escores de zero a três os quais foram somados posté riormente.

8. Percepção sobre a organização: esta variâa vel reflete a opinião do agente de extensão sobre a EMATER-GO em termos de alguns aspectos, quais sejam: a) se este vê a em presa enfatizando ou não a recomendação de pacotes tecnológ cos para os diferentes produtores; b) se percebe o crédito rural contemplando todas as fases do processo produtivo; c) se de acordo com o seu ponto de vista, a Organização é eficiente ou não; e d) se vê perspectivas de desenvolvimento profissio nal dentro da Organização. O escore final constitui-se do so matório dos valores de zero a três atribuídos aos indicadores.

9. Interesse profissional: esta variảvel ex pressa o interesse do agente de extensão em melhorar o seu ní vel de conhecimento técnico. Na realidade, esta variävel com plementa aquela relacionada com a atualização. A diferença está aqui em termos de interesse pessoal futuro. Para tanto, os seguintes indicadores foram considerados: se o agente pro cura ou não "aumentar" os seus conhecimentos na ärea de exten são rural, se ele teria interesse em frequentar um curso de pós-graduação e se ele, pessoalmente, tem reinvindicado mais resultados de pesquisa para a ärea de trabalho em questão. 0 escore final consistiu da soma dos valores de zero a três dos indicadores.

10. Satisfação ocupacional: este item foi consi 
derado em dois aspectos: satisfação ou não sobre o esquema de promoção da EMATER-GO e satisfação ou não com as possibilida des que a empresa fornece para o desenvolvimento intelectual dos extensionistas. Cada indicador recebeu valor zero, um dois e três, os quais foram somados posteriormente.

\section{Aplicação Empírica do Referencial Teórico}

Usualmente, a aplicação empírica do referen cial teórico è observada através das hipóteses. Sejam essas hipóteses de trabalho ou a verificar (Kaplan. 1969), elas de finem um direcionamento analítico "sugerido" pela pröpria teo ria da qual foi derivada. Não obstante, não hã aqui formula ção de hipóteses; as quais poderiam ser derivadas através da suposição sobre as características das unidades que caracter $\underline{i}$ zariam o grupo de elementos que comporiam os diferentes modos de adaptação. Se isto fosse feito, haveria a necessidade, $\underline{\text { fa }}$ to concomitante, de se definir a priori aqueles tipos de adap tação. Por conseguinte, como não é essa a preocupação princí pal desse estudo, ele é eminentemente descritivo, não se utí lizará das hipóteses, o que implica na não definição a priori daqueles modos de adaptação. E importante enfatizar aqui que esta descrição se dará ao longo da análise, a qual se constí tui num dos principais focos deste trabalho. Isto é, se Mer ton, a priori, hipotetizou os sinais +, - e \pm , aqui pretende- se identificar quais as características dos agentes de exten são que são conformistas, inovadores, ritualistas, retraídos 
e rebeldes. Deste modo, ao se fazer um paralelo com a tipolo gia de modos de adaptação individual apresentada por Merton (ver Quadro 1), pode-se fazer algumas modificações : conforme apresentadas no Quadro 2 .

Quadro 2. Tipologia dos Modos de Adaptação dos Agentes de Ex tensão. EMATER-GO 1978 .

\begin{tabular}{llllllllllll}
\hline $\begin{array}{l}\text { Modos de } \\
\text { Adaptação }\end{array}$ & V1 & V2 & V3 & V4 & V5 & V6 & V7 & V8 & V9 & V10 \\
\hline
\end{tabular}

Conformidade

Inovação (é para a formação deste corpo do Quadro 2

Ritualismo que este estudo descritivo espera contri buir)

Retraimento

Rebe1ião

* V1 = experiência profissional; V2 = formação profissional; $\mathrm{V} 3=$ apoio institucional; $\mathrm{V} 4$ = atualização profissional; $\quad \mathrm{V} 5=$ participação na comunidade; V6 = percepção sobre a pesquisa; V7 = percepção sobre a tecnologia recomendada; V8 = percepção sobre a organização; $V 9$ = interesse profissional; $\mathrm{V} 10$ = satis fação ocupacional.

Este Quadro reflete a aplicação do referencial teórico de Merton, onde os V's são as variáveis e os modos de adaptação serão definidos em função dos escores obtidos pelos agentes de extensão em cada variävel. Alẻm disto, poder-se-ä identificar que variảveis caracterizam um ou outro modo de adaptação bem como quais as tendências dos indivíduos se agre gam em um ou outro tipo de adaptação. No desenvolvimento des 
te trabalho a questão teórica que se colocou foi: estariam os individuos destinados a permanecer nestes cinco modos de adap tação? Se existissem quatro, três ou dois grupos, quem e de que grupo passaria para um outro? Esta é uma preocupação deste estudo, a qual não foi considerada por Merton (1968).

3. Técnica de Análise

0 termo análise pode ser compreendido sob dife rentes aspectos. Neste estudo, a análise é descritiva, e co mo tal, não há um delineamento explícito sobre variáveis de pendente e independente: De fato, esta ausência de distinção entre variáveis dependente e independente $\vec{e}$ o que caracteriza este tipo de pesquisa. Além disto, é importante destacar a natureza do tipo de pesquisa que aqui se desenvolve. Esta não utiliza de estatísticas descritivas, como se poderia pressu por. Pelo contrário, há a aplicação de um instrumental mate mático, "Cluster Analysis", o qual permite descrever as unida des de análise através de determinadas categorias. Neste tra balho, esta técnica foi selecionada, porque um dos nossos gran des problemas é o de saber se a amostra formada por extensio nistas da EMATER-GO contém, ou não, grupos de indivíduos distin tos.

As técnicas de "cluster analysis" são basica mente utilizadas para a identificação de grupos. Esses gru pos ou "clusters" podem ser definidos como uma coleção de in 
dividuos ou objetos com certas similaridades (Everitt 1979: 63). E importante que se observe que a análise de "cluster" é essencialmente uma técnica que auxilia na geração de hipóte ses e não no teste das hipóteses. Como os seus mëtodos são essencialmente não-estatísticos, não implicam em teste de significãncia ou possuem teoria de distribuição associada a estes.

Tendo afirmadó acima que a anâlise de "cluster" possui diversas técnicas para a descoberta de estruturas den tro de um complexo corpo de dados, seria de se esperar que al gumas delas (de quatro a seis, pelo menos) fossem utilizadas neste trabalho. Apenas para ilustrar, entre as têcnicas mais utilizadas destacam-se as técnicas de "cluster" hierärquicos; "partitioning techniques"; "Density Search Techniques" e "Clumping Techniques". Dentro de cada uma dessas técnicas há uma grande diversidade de métodos (vêr, por exemplo, Everitt, 1977; Anderberg. 1973; e O'Muircheartaigh \& Payne, 1979). A despeito dessa diversidade, se utilizará neste estudo ape nas uma dessas técnicas, a qual se encontra no pacote SAS (Statistical Analysis System). Sem düvida, este fato ê um ou tro elemento limitante deste estudo, pois o usual é utilizar diversas técnicas para se ter maior "credibilidade" na identi ficação dos agrupamentos. Com respeito a estratégia aqui utí lizada, esta se baseia no conceito de distãncia, pois o progra ma SAS forma os "clusters". e os agrupa sucessivamente entre si a partir da menor distãncia existente entre eles. A dis 
tância entre dois "cluster" é então definida pela distância máxima entre uma observação e um "cluster" e uma observação e o outro "cluster" (SAS user's guide, 1979). 


\section{CAPITULO III}

\section{ESTRATEGIA DA PESQUISA}

Este capítulo trata dos procedimentos através dos quais este estudo foi desenhado e implementado. Algumas das preocupações contidas na estratégia de pesquisa foram a bordadas no capítulo II; tais como informações sobre que no ções da atividade de pesquisa estão envolvidas na perspectiva (funcionalista) utilizada, que tipo de desenho de pesquisa é usado e, que combinação particular de técnicas de pesquisa disponíveis estā sendo empregada. O objetivo deste capítulo é de não só complementar as informações sobre a estratégia de pesquisa aqui utilizada, como também a de oferecer informa ções mais concretas sobre a amostra e a ârea estudadas.

Este trabalho è o resultado de um "survey" rea lizado em 1979, envolvendo os agentes de extensão (extensionis tas) da Empresa de Assistência Técnica e Extensão Rural do E tado de Goiäs (EMATER-GO). Na literatura, um "survey" é en 
tendido como um estudo através do qual são coletadas informa ções de parte de uma população devidamente escolhida com a fi nalidade de representar o todo (vêr, por exemplo, Warwick \& Lininger 1975). Neste estudo descritivo sobre os tipos de comportamentos dos extensionistas da EMATER-GO não existe, co mo ficou explicito no capitulo anterior, um conjunto claro e distinto de variáveis dependente e independente. Embora esta pesquisa não possa ser generalizada, possui um valor por si mesma, isto é, identificar as variáveis que compõem cada modo de adaptação e os valores obtidos pelos agentes de exten são em cada variável, o que permịtirá definir os modos ou ti pos de adaptação. E neste sentido que se pode observar a pro priedade das afirmações de Simon (1969:53) que diz não ser ütil se entender a pesquisa descritiva como um simples está gio para futuros e mais sofisticados usos de técnicas de anâ 1 ise.

1. População e Área Estudadas.

A população total de agrônomos EMATER-GO, di retamente vinculados à ação extensionista era de 107 técnicos. o Quadro 3 apresenta o total destes técnicos de acordo com os cargos que ocupam.

Conforme pode-se observar no Quadro abaixo, dos 107 técnicos, apenas 63 exercem a função precípua de ex tensionista. 
Quadro 3. Total de técnicos por cargos. EMATER-GO 1979.

\begin{tabular}{lc}
\hline \multicolumn{1}{c}{ Cargos } & Nümero \\
\hline Técnicos em Agropecuäria & 63 \\
Chefe de Escritório & 20 \\
Assessores Regionais & 17 \\
Supervisores Regionais & 7 \\
\hline Total Geral & 107 \\
\hline
\end{tabular}

o critério bảsico para a seleção do grupo de individuos para o estudo foi a permanência mínima de um ano de trabalho junto ao escritório local. Julgou-se que um pe ríodo menor que um ano não permitiria ao extensionista uma ví vência capaz de levá-1o a ter um conhecimento maior da região, dos produtores e dos sistemas tecnológicos utilizados para produção agropecuāria. Alêm disso, excluiu-se do grupo os chefes de escritório, assessores e supervisores regionais. Desta forma, o grupo de estudo selecionado por ocasião da pes quisa (setembro, 1979) foi composto de 42 extensionistas.

Dos 42 extensionistas selecionados, dois se re cusaram a dar entrevistas e dois outros foram descartados por distorcerem informações, um outro não foi possível ser 1o calizado na época da pesquisa. Assim, o grupo de estudo f́ㅡ cou reduzido a 37 extensionistas os quais se distribuem por todas as regiões produtivas do Estado de Goiäs. 0 mapa 
apresentado na Figura 1 posiciona os locais visitados pelos entrevistadores.

Observa-se que hã no mapa uma quantidade maior de Regiões do que extensionistas entrevistados. Isto se deve ao fato de que em determinadas localidades um mesmo extensio nista atende a mais de um escritório.

\section{Instrumento de Coleta dos Dados}

0 instrumento básico de pesquisa foi um que $\underline{s}$ tionārio formulado com a preocupação de obter informações so bre os indicadores das dez variāveis (jâ discutidas no capítú 10 2): Experiência Profissional, Formação Profissional, Apoio Institucional, Atualização Profissional, Participação na Comu nidade, Percepção sobre a Pesquisa, Percepção sobre a Organi zação, Interesse Profissional e Satisfação Ocupacional.

Dos 37 entrevistados, 18 permitiram conversar problemas da extensão com o entrevistador usando um gravador portátil. Todas as entrevistas gravadas foram posteriormente analisadas pelo entrevistador. Essa técnica se revelou bas tante ütil para a análise final dos resultados.

Toda a coleta dos dados foi feita pelo autor e um mestre em comunicação para o desenvolvimento. 0 autor fi cou responsável pela coleta de dados fora da ärea do Distrito Federal e o outro entrevistador, com as āreas circunvizinhas a Brasilia . 
Todos os questionärios foram aplicados em uma só etapa, de 3 a 29 de setembro de 1979. Teve-se, durante es te período, todo o cuidado de se evitar a possibilidade de troca de informações entre os elementos da amostra.

Em todo o local da entrevista, o primeiro pas so era sempre o de entrevistar o supervisor regional da EMATER-GO. Na entrevista com ele explicávamos primeiramente o objetivo da pesquisa, o conteúdo de cada típo de comporta mento desenvolvido por Merton (1968) e, após uma conversa mais ou menos demorada sobre cada um desses tipos, solicitávamos para que ele classificasse os elementos a serem entrevistados na categoria de tipo de comportamento que, de acordo com a opinião dele (supervisor regional), mais de perto correspon dia às ações e comportamento de serviço do extensionista. Es ta estratêgia de trabalho veio a se revelar bastante ütil no processo de análise final dos resultados, como se verá no ca pítulo seguinte. Só. após essa entrevista com os supervisores regionais é que se partia para a entrevista com cada um dos elementos da amostra daquela região. Essa sequência só não foi possível ser seguida em poucos casos, mas não se observou qualquer tipo de alteração das informações. De um modo geral, esses supervisores regionais foram muito solícitos e os entre vistadores não tiveram problemas em abordá-1os. Quanto aos extensionistas que compuseram a amostra, a receptividade tam bém foi muito boa, a não ser naqueles quatro casos menciona dos anteriormente neste capítulo. 
Para as respostas anotadas diretamente nos ques tionários, adotou-se o critério de revisão pós-entrevista. o objetivo deste procedimento era o de observar a fidedignidade das respostas e, ao mesmo tempo, o de se evitar ao máximo os valores ausentes ("missing values"). Mesmo com a utilização sistemätica deste procedimento, alguns valores ausentes foram localizados quando da elaboração do mapa final dos resultados. Por duas vezes, foi necessārio voltar aos entrevistados para observações complementares.

Para medição foi utilizada uma escala de zero a. três da seguinte forma:

\begin{tabular}{cl} 
Escores & \multicolumn{1}{c}{ Significação } \\
0 & Quando não houve resposta \\
1 & Quando a resposta foi negativa \\
2 & Quando a resposta ficou situada en \\
& tre "sim" e "não" (regular) \\
3 & Quando a resposta foi positiva
\end{tabular}




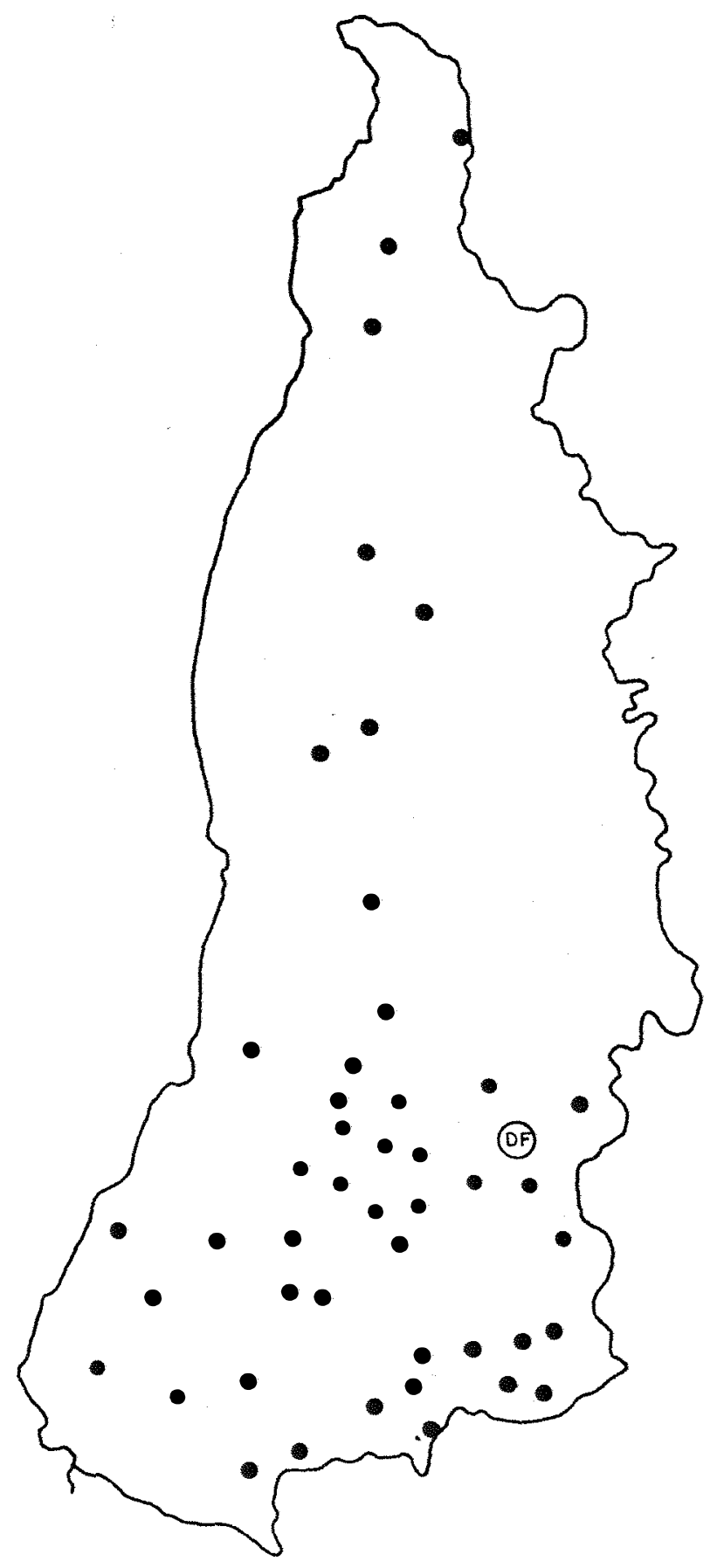

FIGURA 1: Locais Visitados pelos Entrevistadores. Estado de Goiás. 


\section{CAPITULO IV}

\section{ANÁLISE DOS RESULTADOS}

Nos capitulos anteriores, ficou enfatizado que um "survey" descritivo é frequentemente idêntico, em suas ope rações, a um "survey" explicativo. A distinção entre os dois tipos de pesquisa é mais um problema de intenção de objetivos e de uso dos dados do que propriamente de conteúdo (para uma defesa mais completa desta posição veja, por exemplo, War wick \& Lininger. 1975). Uma tarefa bảsica da pesquisa descri tiva (tanto quanto da pesquisa explicativa) é a conceituação do fenômeno a ser estudado. Neste trabalho, uma preocupação essencial é com os tipos de adaptação característicos dos a gentes de extensão da Empresa de Assistência Técnica e Exten são Rural do Estado de Goiās (EMATER-GO). 0 capítulo II mos trou que esses tipos são. dados por Merton (1968). Se Merton hipotetizou os comportamentos dos agentes sociais diante de metas culturais e de meios institucionalizados, a preocupação 
deste trabalho è diferente, ou seja, $\vec{e}$ a de estudar as tendên cias dos individuos se agregarem em um ou outro tipo de adap tação dentro da EMATER-GO. Mas esta tarefa, como tem-se repe tido, é diferente da tarefa de explicar o fenômeno. Este tra balho, apesar de ter a sua própria razão de ser através dos seus objetivos internos, tambëm coloca as bases para a poste rior consecução de outros objetivos, incluindo a explicação, o teste de hipóteses, a avaliação, a prediçăo e o desenvolvi mento de indicadores. Esta relação entre estudos descritivos e explicativos é sintetizada, de uma forma bastante feliz, pelo professor Herbert Hyman. Ele diz:

"The descriptive survey is thus a training ground for the development of skill in conceptualization of the phenomenon and in the treatment of the findings in relation to error factors, both essential to effective analysis of explanatory surveys. But there is still another feature of the descriptive survey which is especially valuable for ultimate work in the design and analysis of explanatory surveys. Out of the findings of such surveys often comes the basis for the formulation of fruitful hypotheses about phenomena, or at least for some reduction in confusion about phenomena" (Hyman, 1955:77-78).

O primeiro objetivo deste trabalho foi o de ca tegorizar empiricamente as unidades de anālise, isto é, os ex tensionistas da EMATER-GO, de acordo com determinados tipos de comportamento adaptativos. Esses tipos são dados e desen volvidos por Merton (1968:212-231). Tendo, pois, os cinco ti pos de adaptação dos indivíduos dentro de uma organização (Conformidade, Inovação, Ritualismo, Retraimento e Rebelião) 
sido dados teoricamente bem como uma lista de dez variáveis (experiência profissional, formação profissional, apoio insti tucional, atualização profissional, participação na comunida de, percepção sobre a pesquisa, percepção sobre a tecnologia recomendada, percepção sobre a organização, interesse profis sional e satisfação ocupacional) identificando algumas carac terísticas dos agentes de extensão e suas percepções sobre a instituição em que trabalham utilizou-se a análise de "clus ter" para se estudar os agrupamentos dos individuos dentro dos cinco tipos de adaptação. 0 resultado dessa classifica ção é mostrado através da Tabela 1 .

Tabela 1. Média das Variáveis nos Diferentes "Clusters".

\begin{tabular}{|c|c|c|c|c|c|c|c|c|c|c|}
\hline 'Clusters & V1 & V2 & V3 & V4 & V5 & V6 & V7 & V8 & V9 & V10 \\
\hline Cluster I & 7.8 & 3.0 & 6.8 & 4.5 & 7.8 & 1.0 & 4.5 & 6.5 & 4.5 & 2.0 \\
\hline Cluster II & 2.5 & 3.3 & 9.3 & 5.5 & 6.0 & 1.8 & 4.8 & 4.8 & 4.0 & 2.3 \\
\hline Cluster III ${ }^{* *}$ & 13.0 & 4.0 & 11.0 & 9.0 & 7.0 & 3.0 & 6.0 & 6.0 & 7.0 & 4.0 \\
\hline Cluster IV & 3.1 & 3.3 & 7.9 & 5.6 & 6.1 & 1.3 & 4.4 & 8.4 & 5.2 & 2.8 \\
\hline Cluster V & 2.0 & 3.7 & 10.4 & 8.7 & 6.7 & 1.7 & 4.4 & 9.8 & 5.8 & 3. \\
\hline
\end{tabular}

* V1=experiência profissional; V2=formação profissional; V3= apoio institucional; V4=atualização profissional; V5=parti cipação na comunidade; V6=percepção sobre a pesquisa; V7= percepção sobre a tecnologia recomendada; $V 8=$ percepção so bre a organização; $\mathrm{V} 9=$ interesse profissional; $\mathrm{V} 10=$ satisfa ção ocupacional . 
A Tabela I é resultante da aplicação da técni ca de "cluster" aos dados empíricos. Como decorrência do pró prio processo analítico, a fixação dos números de "clusters" pode ser considerada como sendo inicialmente arbitrária. Es ta determinação poderia ser em torno de seis, quatro ou outro número qualquer. Não obstante, como há uma orientação teôri ca em torno de 5 "clusters", aquela fixação deixa de ser to talmente arbitrária. Este totalmente, é claro, refere-se ou é decorrente de um quadro'referencial teórico. Deste modo, hâ inicialmente uma preocupação em interpretar esses resulta dos sob a perspectiva empírica da técnica analítica para, num estágio posterior, avaliar a consonância teórica desta class ficação empírica.

Numa anảlise mais detida sobre a Tabela 1 pelo menos um padrão importante de resposta para a análise se res salta. O "cluster" 5. é basicamente composto por extensionis tas mais jovens em termo de experiência profissional (valor médio 2), imediatamente seguido pelos extensionistas que com põem o "cluster" 2 (valor médio 2.5). Outro dado importante é que os extensionistas que fazem parte do "cluster" 5 pos suem maior formação profissional, recebem maior apoio institu cional e obtiveram maior atualização profissional que os de mais extensionistas pertencentes aos outros grupos. (Como o "cluster" 3 é formado apenas por um extensionista ele não es tá sendo considerado nesta anālise de valores médios). Também os extensionistas classificados no "cluster" 5 possuem um a 1 
to grau de satisfação ocupacional (3.8) quando comparados com aqueles do grupo 4 (2.8), grupo 2 (2.3) e do "cluster" 1 (2.0). Em termos de interesse profissional o valor médio de 5.9 só é aproximado pelos extensionistas do "cluster" 4 (5.2) e muito distante do valor médio dos extensionistas pertencentes ao "cluster" $3(4.0)$. A percepção sobre a organização é bem a ta entre os extensionistas do "cluster" 5 (9.8), principalmen te quando comparada com aquela do "cluster" 2 (4.8). Contudo, os extensionistas do "cluster" 5 tem um baixo nível de percep ção sobre a tecnologia recomendada que eles têm a função de difundir. Este mesmo baixo nível de percepção é seguido pelo "cluster" 4 (4.4). O maior grau de percepção sobre a tecnolo gia recomendada foi obtido por aqueles extensionistas que for mam o "cluster" $2(4.8)$. Mas, se existe um baixo nível de percepção sobre a tecnologia recomendada entre os extensionis tas do "cluster" 5, o grau de percepção sobre a pesquisa, en quanto instituição (1.7), é compatível com o mesmo grau obtido pelo "cluster" 2 (1.8), o mais alto sob esta variável. A me nor percepção ficou com os extensionistas do "cluster" 1 (1.0). A quantos extensionistas esses valores médios correspondem? A Tabela 2 responde a essa questão apresentando a distribuição dos extensionistas nos cinco "clusters".

Uma anālise da Tabela 2 revela que o "cluster" quatro concentrou $51.4 \%$ do total da amostra, revelando, por tanto, a maior concentração dos extensionistas nesse tipo es pecífico de comportamento. O "cluster" número cinco abrangeu 
Tabela 2. Distribuição dos Extensionistas em Cinco "Clusters"

\begin{tabular}{ccc}
\hline Clusters & Nümero de Extensionistas & $\%$ \\
\hline 1 & 4 & 10.8 \\
2 & 4 & 10.8 \\
3 & 1 & 2.7 \\
4 & 19 & 51.4 \\
5 & 9 & 24.3 \\
\hline T o t a 1 & 37 & 100.0 \\
\hline
\end{tabular}

$24.3 \%$, os "clusters" um e dois obtiveram cada um $10.8 \%$ e o "cluster" número três representou apenas 2.7\% da amostra. Mas um problema bảsico se apresenta na anảlise das Tabelas 1 e 2: a quais tipos de comportamento correspondem os "clusters" de 1 a 5? Para termos acesso a esta identificação foi utilizada a esta altura as entrevistas obtidas com os supervisores re gionais referidas no capitulo III. Cada supervisor regional havia, baseado na definição dos tipos de comportamento, dis tribuído os extensionistas em cada uma das categorias (tipos). A partir da maior recorrência (concordância) de respostas en tre a classificação dos supervisores regionais (utilizados aqui como juízes) e a classificação da anālise de. "cluster" se teve, então, um acesso racional sobre que tipos de compor tamento estavam por traz dos "clusters" de 1 a 5 apresentados nas Tabelas 1 e 2 . 
O Quadro 4 abaixo apresenta para cada observa ção da amostra, a classificação dos extensionistas entre os diferentes tipos de comportamento. Como o padrão de resposta bäsico para a identificação dos cinco tipos de comportamento foi aquele do juíz (supervisor regional), a decisão na identi ficação dos "clusters" foi tomada a partir da maior recorrên cia de individuos classificados anteriormente como nas catego rias de conformidade, inovação, ritualismo, retraimento e re belião. Pelo Quadro 4 percebe-se,claramente, a existência de 20 concordâncias e 17 discordâncias. Esse padrão de concor dância/discordância pode ser melhor analisado através da Tabe 1a 3. Um ótimo padrão de concordância seria mostrado se os números dispersos pelas diferentes celas da Tabela estivessem concentrados na sua diagonal. Na verdade isso só ocorre em relação à classificação feita para a categoria denominada de ritualismo. Nessa categoria ambos, juízes e "cluster", colo caram 19 extensionistas da amostra onde, desses 19, 13 exten sionistas ou seja $68.4 \%$ ( $35.14 \%$ da amostra) foram designados como ritualistas pelos juizes e pela análise de "cluster". Se ria interessante destacar que quatro extensionistas classif cados como ritualista através da análise de "cluster" foram incluídos na categoria de inovadores pelos juizes. A segunda categoria de maior concordância diz respeito aos inovadores. Os juízes identificaram 21,62\% dos extensionistas e a técnica de "cluster" $24,32 \%$ entre os 37 elementos da amostra. A con cordância entre esses dois critérios de classificação diz res 
Quadro 4. Classificação dos Indivíduos da Amostra Feita Pelos Juízes e Pela Anälise de "cluster".

\begin{tabular}{|c|c|c|}
\hline Indivíduos & Juízes & "Cluster" \\
\hline
\end{tabular}

\begin{tabular}{|c|c|c|c|c|}
\hline 1 & Rebelião & Retraimento & & - \\
\hline 2 & Ritualismo & Ritualismo & + & \\
\hline 3 & Ritualismo & Ritualismo & + & \\
\hline 4 & Ritualismo & Conformismo & & - \\
\hline 5 & Ritualismo & Ritualismo & + & \\
\hline 6 & Rebelião & Inovação & & 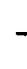 \\
\hline 7 & Ritualismo & Ritualismo & + & \\
\hline 8 & Ritualismo & Conformismo & & 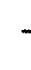 \\
\hline 9 & Inovação & Inovação & + & \\
\hline 10 & Conformismo & Inovação & & \\
\hline 11 & Conformismo & Conformismo & + & \\
\hline 12 & Ritualismo & Ritual ismo & + & \\
\hline 13 & Inovação & Ritual ismo & & \\
\hline 14 & Rebelião & Retraimento & & \\
\hline 15 & Ritual ismo & Ritualismo & + & \\
\hline 16 & Ritualismo & Retraimento & & \\
\hline 17 & Inovação & Ritualismo & & \\
\hline 18 & Ritualismo & Ritualismo & + & \\
\hline 19 & Ritualismo & Ritualismo & + & \\
\hline 20 & Conformismo & Conformismo & + & \\
\hline 21 & Ritual ismo & Inovação & & \\
\hline 22 & Inovação & Ritualismo & & \\
\hline 23 & Inovação & Inovação & + & \\
\hline 24 & Ritualismo & Ritualismo & + & \\
\hline 25 & Ritualismo & Ritualismo & + & \\
\hline 26 & Ritual ismo & Retraimento & & \\
\hline 27 & Ritualismo & Ritualismo & + & \\
\hline 28 & Ritualismo & Ritualismo & + & \\
\hline 29 & Retraimento & Inovação & & \\
\hline
\end{tabular}


Continuação do Quadro 4

\begin{tabular}{cllcc}
\hline Indivíđuos & Juízes & "Clusters" & $\begin{array}{c}\text { Concordância. } \\
(+)\end{array}$ & $\begin{array}{c}\text { Discordância } \\
(-)\end{array}$ \\
\hline 30 & Ritualismo & Inovação & & - \\
31 & Rebelião & Rebelião & + & \\
32 & Inovação & Inovação & + & - \\
33 & Rebelião & Ritualismo & & - \\
34 & Ritualismo & Ritualismo & + & - \\
35 & Inovação & Ritualismo & & \\
36 & Retraimento & Ritualismo & & + \\
37 & Inovção & Inovação & + & \\
\hline
\end{tabular}

Tabela 3. Comparação da Classificação dos Extensionistas de Acordo com a Análise de "cluster" com a dos Supervisores Regionais (Juí zes) .

\begin{tabular}{l|cccccc}
\hline Juízes & $\begin{array}{r}\text { Retrai } \\
\text { mento }\end{array}$ & $\begin{array}{c}\text { Confor } \\
\text { mismó }\end{array}$ & $\begin{array}{c}\text { Rebe } \\
\text { lião }\end{array}$ & $\begin{array}{c}\text { Ritua } \\
\text { lismó }\end{array}$ & $\begin{array}{c}\text { Inova } \\
\text { ção- }\end{array}$ & Total \\
\hline Retraimento & 0 & 0 & 2 & 2 & 0 & 4 \\
Conformismo & 0 & 2 & 0 & 2 & 0 & 4 \\
Rebelião & 0 & 0 & 1 & 0 & 0 & 1 \\
Ritualismo & 1 & 0 & 1 & 13 & 4 & 19 \\
Inovação & 1 & 1 & 1 & 2 & 4 & 9 \\
\hline Totais & 2 & 3 & 5 & 19 & 8 & 37 \\
\hline
\end{tabular}


peito à indicação de 4 extensionistas para a categoria de ino vadores.

Em contraposição, a maior discrepância encontrada foi em referência à categoria de retraídos e de rebe 1ião. Com relação à categoria de retraídos, os 10,81\% da amostra em estudo classificados nessa categoria pela anälise de "cluster" foram alocados nas categorias de rebelião (2 de les) e ritualismo (2 deles) pelos juízes. Por sua vez, ' os $5,41 \%$ dos extensionistas em estudo classificados na categoria de retraídos pelos juízes foram distribuídos entre as catego rias de ritualismo (1) e de inovação (1) pela análise de "cluster". Em relação à categoria de rebelião, a técnica de "cluster" classificou $2,7 \%$ dos extensionistas estudados e os juízes indicaram $13,51 \%$ desses mesmos elementos para esta ca tegoria.

O teste de qui-quadrado, que poderia ser de utilidade neste caso, é desaconselhado devido ao fato de que mais de $20 \%$ das celas da Tabela 3 possuirem valores esperados inferiores a cinco. Sendo a tabela muito esparsa o qui-qua drado deixa, então, de ser um teste vâlido.

A comparação das duas classificações (juízes e "cluster") revela claramente a concentração dos indivíduos en trevistados no tipo de comportamento denominado de ritualis mo. A classificação mais problemática foi aquela da catego ria rebelião. 
Verificado a esta altura o tipo de comporta mento a que corresponde cada um dos cinco "cluster" a Tabela 1 inicial assume então as configurações da Tabela 4 abaixo.

Tabela 4. Média das Variáveis nos Diferentes Tipos de Compor tamento.

\begin{tabular}{lrrrrrrrrrr}
\hline $\begin{array}{l}\text { Variaveis* } \\
\begin{array}{l}\text { Tipos de } \\
\text { Comportamento }\end{array}\end{array}$ & V1 & V2 & V3 & V4 & V5 & V6 & V7 & V8 & V9 & V10 \\
\hline Retraimento & 7.8 & 3.0 & 6.8 & 4.5 & 7.8 & 1.0 & 4.5 & 6.5 & 4.5 & 2.0 \\
Conformidade & 2.5 & 3.3 & 9.3 & 5.5 & 6.0 & 1.8 & 4.8 & 4.8 & 4.0 & 2.3 \\
Rebelião** & 13.0 & 4.0 & 11.0 & 9.0 & 7.0 & 3.0 & 6.0 & 6.0 & 7.0 & 4.0 \\
Ritualismo & 3.1 & 3.3 & 7.9 & 5.6 & 6.1 & 1.3 & 4.4 & 8.4 & 5.2 & 2.8 \\
Inovação & 2.0 & 3.7 & 10.4 & 8.7 & 6.7 & 1.7 & 4.4 & 9.8 & 5.8 & 3.8 \\
\end{tabular}

*V1=experiência profissional; V2=formação profissional; V3= apoio institucional; V4=atualização profissional; V5=parti cipação na comunidade; V6=percepção sobre a pesquisa; V7= percepção sobre a tecnologia recomendada; V8=percepção só bre a organização; V9=interesse profissional; V10=satisfa ção ocupacional.

**Há apenas um extensionista neste tipo de comportamento.

Com a identificação dos "clusters" na Tabela 4 é visível que os inovadores possam vir a desempenhar um papel verdadeiramente vitalizador para a organização (EMATER-GO) . Esses inovadores possuem uma ótima percepção da organizaçāo, têm um grande interesse e formação profissionais, além de de 
monstrarem grande satisfação profissional, principalmente quando comparados em seu conjunto com a categoria teoricamen te funcional para a Empresa, os conformistas. Os dados da Ta bela 4 indicam que os extensionistas classificados como inova dores não possuem uma boa percepção da tecnologia que recomen dam. Infelizmente, os dados não conseguem indicar o tipo des sa resistência. Os extensionistas classificados como retraí do, são os de maior experiência profissional (7.8), seguidos pelos ritualistas (3.1), conformistas (2.5) e inovadores (2.0). o grupo que recebe o maior apoio da organização é o dos inova dores (10.4), seguido dos conformistas (9.3), ritualistas (7.9) e retraídos (6.8).

O segundo objetivo deste trabalho foi o de ve rificar se as formas adaptativas de comportamento estão em conformidade com os padrões de organização e funcionamento da EMATER-GO. Sendo este o caso, é de se esperar que parte con siderável dos extensionistas fosse localizada (tanto pela aná lise de "cluster" quanto pela indicação dos juízes) na catego ria de conformismo, a qual reflete um tipo de comportamento orientado para os valores básicos e estratégias de ação da EMATER-GO. Para este tipo de comportamento os juizes indica ram (veja-se a Tabela 3) 8,11\% dos extensionistas da amostra (o que perfaz um total de três) e a análise de "cluster" in dicou $10,81 \%$ ou seja 4 extensionistas. A alta indicação de extensionistas para as categorias de ritualismo. (51,35\%) e inovação $(21,62 \%$ indicados pelos juízes e $24,32 \%$ indicados pe 
la técnica de "cluster") mostra uma grande predominância dos tipos de comportamento divergentes em relação à organização sobre o tipo mais relacionado com os padrões de organização e funcionamento da EMATER-GO. Para se aceitar que as formas adaptativas de comportamento estivessem afins com os padrões de funcionamento da EMATER-GO,tanto os juízes quanto a análí se de "cluster" deveriam ter indicado uma grande percentagem da amostra de extensionistas para a categoria de conformismo e com um bom grau de concordância quanto as indicações, fato que não ocorreu.

0 terceiro objetivo do trabalho foi o de procu rar estabelecer as tendências de concentração dos diferentes tipos de adaptação. A análise feita até este momento, para atender aos requerimentos dos dois primeiros objetivos, teve a característica de uma análise estātica, isto é, a preocupa ção básica foi a de revelar uma distribuição presente numa ta bela e relativa à distribuição dos extensionistas dentro dos cinco tipos de comportamento propostos por Merton (1968). A análise deste terceiro objetivo leva a considerações de ordem mais dinâmica. Uma das questões pertinentes neste tipo de anālise assume o seguinte formato: existindo três ou quatro tipos de comportamento dentro da EMATER-GO, quais seriam as tendências de união entre esses tipos? Extensionistas hoje pertencentes ao tipo de comportamento $x$ tenderiam para o tipo "y" ou tipo "z" de comportamento? Valendo-se da anālise de "cluster", este é o tipo básico de anālise a que nos leva es 
te terceiro objetivo.

A pressuposição básica, a qual justifica a ne cessidade de se investigar essas tendências, é de que os ex tensionistas tenderiam a se agrupar aos outros elementos da or ganização, visto que a sua posição inicial talvez não fosse a mais viável. Não obstante, hả necessidade de se faror uma ressalva. Isto é, a própria técnica de "cluster" não pernite identificar que agrupamento tenderia a se unir ao outro. Há apenas o resultado de que os agrupamentos se unem. E em ou tras palavras, não é possível identificar se o comportamento $x$ e aquele que tende para o y, ou vice-versa. Sabe-se apenas que eles se unem.

Tendo esta 1 imitação em mente, observa-se que ao agrupar os elementos da amostra em quatro grupos, a técni ca de "cluster" tende a agregar apenas os elementos que estão nos modos de adaptação designados como retraídos e conformis tas. O resto do agrupamento permaneceu como estava. Por sua vez, na identificação de três agrupamentos, as categorias ri tualista e inovadores se unem, e apenas com dois agrupamentos é que o extensionista classificado como rebelde se une àque les que compuseram o agrupamento dos retraidos e conformistas na formação das quatro categorias anteriormente citadas.

Pode-se dizer que, empiricamente, tem-se uma ten dência para obter dois grandes agrupamentos no final. Um com posto por 9 extensionistas e o outro constituído por 28 exten 
sionistas. Teoricamente, esta tendência revela alguns aspec tos interessantes. Por exemplo, a união entre retraídos e conformistas e a posterior união a este agrupamento do único elemento classificado como rebelde. Deste modo, hả a evidên cia, como a própria análise funcionalista sugere, de "acomoda ção" dos elementos "estranhos" ao sistema pelo pröprio siste ma. Se se assume a pressuposição de que o comportamento fun cional para a EMATER-GO é o conformista, poder-se-á dizer que tanto os retraídos como os rebeldes tendem a se adaptar naque las normas e padrões de comportamento apregoados pela Empresa. Entretanto, é importante ter em mente que apenas 9 extensio nistas se enquadram nesta situação. Da amostra em estudo, 28 deles estariam agrupados sob as categorias de ritualista e inovador. A princípio, estas categorias não foram considera das como funcionais para a Empresa, pois, de um modo ou de ou tro, elas se constituem em comportamentos divergentes. Não obstante, ao compará-1as conceitualmente, poder-se-ia pressu por que o inovador fosse preferível ao ritualista. Em conso nância com esta pressuposição, poder-se-ia dizer que os ritua listas tenderiam a inovadores. E importante deixar bem explí cito que todas as tendências aqui analisadas são vâlidas em função das pressuposições assumidas. Se uma dessas pressupo sições deixar de ser vâlida, o resultado serā incorreto.

Diante do que foi exposto, é inegável o valor limitado das anảlises das tendências. Considerando que a pró pria técnica de anālise não permite melhores inferências, su 
gere-se que a utilização de outro procedimento analítico se ria mais viável para elucidar aqueles aspectos. Por exemplo, a utilização do modelo "Markov Chain" (Bartos 1967) permití ria sobrepor todas as limitações derivadas da técnica de "cluster"(1). Além do modelo "Markov Chain" permitir a iden tificação dos elementos que passariam de um estágio para ou tro (onde poder-se-ia considerar cada modo de adaptação como um estágio), há a possibilidade de analisar a probabilidade que os elementos teriam de mudar de estágio bem como a de per manecer em um estágio.

0 quarto e ültimo objetivo proposto por este trabalho foi o de dar sugestões à EMATER-GO, em termos de rees truturar o comportamento dos agentes de extensão, de tal for ma que aumente a probabilidade deles se adaptarem de forma construtiva aos princípios da Empresa. Baseado nos dados ana lisados, uma sugestão básica que se oferece é da EMATER-GO se envolver mais com a fase de geração e desenvolvimento da tec nologia, isto è, de fazer com que o seu corpo técnico não só se comunique com a pesquisa para "aprender" sobre as tecnolo gias geradas, mas principalmente para "influir" sobre aquilo que vai ser e que está sendo gerado como tecnologia agropecuáa ria. A análise da Tabela 4 demonstrou que aqueles extensio nistas mais jovens profissionalmente, de maior solidez profis sional, de maior atualização e interesse profissional são os que menos confiam no produto da pesquisa. As causas desta fa 1 ta de confiança não aparecem na análise, mas se acredita que 
com maior articulação pesquisa/extensão (e consequentemen te maior influência da extensão no produto final da pesquisaa tecnologia agropecuäria) a percepção sobre a pesquisa recó mendada venha a melhorar.

Uma outra sugestão que se pode fazer a EMATER é sobre a formação profissional dos seus agentes de extensão. Em geral, a média nos diferentes grupos é baixa. Deste modo, a EMATER não está selecionando elementos que freqủentaram cur sos de extensão a nível de graduação, ou não está propiciando cursos para a especialização dos agentes da região em estudo. Além disto, há o caso de seleção desses profissionais sem que eles tenham outra opção de trabalho. Considerando esses as pectos, a sugestão que se faz é exatamente sobre o processo de seleção utilizado na contratação dos seus profissionais Se esta seleção não visar as qualidades técnico-científicas € predisposições pessoais para a execução da tarefa de extensio nista, a organização será prejudicada com a atividade desen volvida por aquele elemento que ela selecionou.

Do mesmo modo, a média de atualização profis sional para as categorias de retraidos, conformistas e ritua listas é baixa. Isto evidencia que os agentes de extensão não estão recebendo publicações com informações adequadas pa ra o desenvolvimento das suas tarefas. Neste sentido, a EMATER-GO deveria incrementar a divulgação e o acesso desses técnicos a tais boletins. 
Um outro fato crucial que pode ser destacado na Tabela 4 é a insatisfação ocupacional dos agentes de exten são em todos os modos de adaptação. A média é excessivamente baixa, o que demonstra a insatisfação com o critério promocio nal da Empresa e com a realização intelectual que a atividade do extensionista requer. Este aspecto é fundamental, uma vez que esta insatisfação pode repercutir negativamente no desem penho da tarefa do extensionista. Deste modo, sugere-se que a Empresa reveja, principalmente, o critério de promoção dos seus técnicos. 


\section{NOTAS DO CAPITULO IV}

(1) A razão principal da não utilização do modelo "Markov Chain" neste estudo foi devido ao fato de que esta técnica requer um desenho de pesquisa que envolva um levantamento de da dos ao longo do tempo. 


\section{CAPITULO V}

\section{CONCLUSOES}

Esta dissertação envolveu o estudo exploratọ rio-descritivo dos tipos de comportamento dos extensionistas da Empresa de Assistência Técnica e Extensão Rural do Estado de Goiâs (EMATER-GO). O problema básico de estudo foi formu lado através da pergunta: quais são os tipos de adaptação ca racterísticos dos agentes de extensão da EMATER-GO? A respos ta para esta questão-problema foi buscada em forma de tendên cia. Isto é, se no momento " $t$ " - o momento da pesquisa - a distribuição dos extensionistas era "x", quais as tendências de mudança dessa distribuição no momento "t $+1 "$ ?

o desenvolvimento teórico-metodológico do tra balho, além de estar dirigido para uma resposta da questãoproblema procurou também se vincular ao atendimento de quatro objetivos bâsicos: (1) categorizar empiricamente as unidades de anâlise de acordo com determinados tipos de comportamento 
adaptativos; (2) verificar se as formas adaptativas de compor tamento estavam em conformidade com os padrões de organização e funcionamento da EMATER-GO; (3) procurar estabelecer as ten dências de concentração dos diferentes tipos de adaptação; e (4) oferecer sugestões à EMATER-GO, em termos de reestrutura ção do comportamento dos agentes de extensão, de tal forma que a probabilidade deles se adaptarem de forma construtiva aos princípios da Empresa seja aumentada.

0 enfoque teórico desta dissertação foi funda mentado na proposição de Merton (1968) sobre os tipos de adap tação individual. O que aqui se fez foi a adequação do ins trumental teórico de Merton a uma realidade especifica, isto é, àquela da assistência técnica e extensão rural do Estado de Goiās. A pressuposição teórica de Merton (1968:23) de que "... a estrutura social opera a fim de exercer pressões sobre os individuos" foi assumida por este trabalho. A preo cupação bảsica de Merton (1968) era com o estudo da estrutura social, do ponto de vista da anālise estrutural. Assim é que as definições teóricas (conformidade, inovação, ritualismo, retraimento e rebelião) foram derivadas em termos das metas culturais e dos meios institucionalizados. Como este estudo não empregou aqueles parâmetros, considerou-se um conjunto de variāveis (experiência profissional, formação profissional, apoio institucional, atualização profissional, participação na comunidade, percepção sobre a pesquisa, percepção sobre a tecnologia recomendada, percepção sobre a organização, inte- 
resse profissional e satisfação ocupacional) que identifica ram algumas características dos agentes de extensão, bem como as suas percepções sobre a organização em que trabalham. Dí ferente de Merton, este estudo não formulou situações hipotẹ ticas para os vários tipos de adaptação. Uma das contribui ções deste estudo foi a de identificar quais as variāveis que compõem os tipos de adaptação, bem como os valores obtidos pe los extensionistas em cada uma daquelas variáveis.

Baseado num grupo de estudo de 37 extensionis tas de todas as regiões do Estado de Goiás e nas dez variāa veis jả mencionadas, este estudo, utilizando-se da técnica de "cluster", classificou 4 extensionistas no tipo de retraido, 4 no tipo de conformismo, 1 no tipo de rebelião, 19 no tipo de ritualismo e 9 no tipo de inovação. Ficou claro no estudo das tabelas do capitulo de análise que, embora o tipo confor mista seja aquele que aceita integralmente as políticas da or ganização, ele não é o mais capaz profissionalmente ou pelo menos o mais atualizado agronomicamente e em termos de difu são de tecnologia. O tipo inovador se mostrou mais capaz que os conformistas, mas trazendo uma desconfiança em relação à tecnologia que difundem para os produtores rurais.

$\mathrm{Na}$ análise sobre as tendências de junção dos diferentes tipos de comportamento foi verificada a evidência, como a própria anâlise funcionalista sugere, de "acomodação" dos elementos "estranhos" ao sistema pelo pröprio sistema. A tendência foi para se obter dois grandes grupos no final. Um 
composto por 9 extensionistas e o outro constituído por 28 ex tensionistas. E importante deixar claro que as análises de tendências feitas no Capítulo IV são vâlidas em função das pressuposições que são assumidas no trabalho. Se uma daque las pressuposições deixasse de ser vâlida, o resultado fica ria incorreto. Essas anảlises, portanto, têm um caráter limi tado. A utilização do modelo "Markov Chain" não foi feita de vido ao fato de que aquela técnica requer um desenho de pes quisa que envolva um levantamento de dados ao longo do tempo, diferente, portanto do desenho de "survey" realizado para es te estudo.

Como consequência da análise dos dados,algumas sugestões à EMATER-GO foram apontadas, tais como: (1) a de es timular o seu corpo técnico com a finalidade de não só se có municar com a pesquisa para "aprender" sobre as tecnologias geradas, mas principalmente para "influir" sobre aquilo que vai ser e que está sendo gerado como tecnologia agropecuária; (2) a de aumentar a formação profissional dos seus agentes de extensão; (3) a de adaptar o processo de seleção utilizado na contratação dos seus profissionais para que enfatize as qua lidades técnico-científicas e de predisposições pessoais para a execução da tarefa de extensionista; (4) a de incrementar a divulgação e o acesso de publicações técnicas para os agentes de extensão; e, (5) a de estabelecer um critério promocional dos técnicos de extensão que estimule e compatibilize a rea lização intelectual com a atividade de extensão. 
Durante o texto e sempre que oportuno, procu rou-se indicar as limitações deste trabalho de pesquisa. Mas, pelo menos, dois grandes grupos de limitações podem ser clas sificados: aquelas 1 imitações de ordem teōrica e aquelas de ordem mais caracteristicamente metodológicas. Entre as 1 imi tações de ordem teórica destaca-se o caráter relativamente a-teórico das dez variáveis utilizadas. O Capítulo I I apresen td, contudo, uma justificativa para esta opção.

Entre as 1 imitações metodológicas destaca-se a utilização da técnica de "cluster" para a análise das tendên cias em lugar, por exemplo, do modelo "Markov Chain". A juㅗ tificativa básica para esta decisão se deveu ao fato de que os dados disponíveis não foram levantados ao longo do tempo.

Para a realização de estudos posteriores nesta direção sugere-se a adoção de um modelo de pesquisa que possi bilite a obtenção de dados em diferentes períodos de tempo . A utilização de tal modelo de pesquisa facilitará em muito a tarefa de se estudar as tendências de comportamento dentro da organização. Outra sugestão é a de que se utilize o estudo comparativo entre duas organizações. Este tipo de estudo po derá adicionar importantes pontos para a anảlise. 


\section{B IBL IOGRAFIA}

ASSOCIAÇAOO BRASILEIRA DE CREDITO E ASSISTENCIA RURAL. Sistema Brasileiro Cooperativo de Extensão Rural, 1960. Plano Dire tor; quinquênio 1961-1965. Rio de Janeiro, 279 p. il.

ASSOCIAÇAO BRASILEIRA DE CREDITO E ASSISTENCIA RURAL, 1959.

ABCAR 3 Anos de Atividades: Síntese das Principais Ativida des do Sistema Cooperativo de Extensão Rural e Crédito Supervisionado. Rio de Janeiro. 20p.

ASSOCIAÇÃO DE CREDITO E ASSISTENCIA RURAL, (s.d.). Dez Anos. a Serviço do Povo Rural de Minas Gerais, 1949-1979. Belo Horizonte, $48 \mathrm{p}$, il.

BARTOS, 0.J., 1967. Simple Models of Group Behavior. New York, Columbia University Press.

CAMPElO, A.M.C., 1973. Estratégia e Organização de Extensão Rural. In: PASTORE, J. Agricultura e Desenvolvimento. Rio de Janeiro, APEC, p.217-30. 
EMPRESA DE ASSISTENCIA TECNICA E EXTENSAOO RURAL DO ESTADO DE GOIAS, 1978. Programa Estadual de Assistência Técnica e Extensão Rura1. PROATER. Goiânia, 62p. il .

EMPRESA DE ASSISTENCIA TECNICA E EXTENSAOO RURAL DO ESTADO DE GOIÁS, 1979. Programa Estadual de Assistência Técnica e. Extensão Rural. PROATER. Goiânia. 55p. il .

EMPRESA DE ASSISTENCIA TECNICA E EXTENSAOO RURAL DO ESTADO DE GOIÁs. (s.d.). Relatório de Atividades, 1978. Goiânia. 25p. il .

EMPRESA DE ASSISTENCIA TECNICA E EXTENSAOO RURAL DO ESTADO DE GOIÂS, 1980. Relatörio de Atînidades 1979. Goiânia. 40p. il .

EVERITT, B., 1977. Cluster Analysis. London, Heinemann. Educational Books.

EVERITT, B.S., 1979. Cluster Analysis. In: O 'MUIRCHEARTAIGH, A. e C. PAYNE, ed. Exploring Data Structures. New York, John Wiley \& sons, p.63-88.

FICHTER, J.H., 1969. Sociologia. São Paulo: Editora Herder.

FIRTH, R., 1965. "Organização Social e Estrutura Social". Fernando Henrique Cardoso e Octávio Ianni, Homem e Sociedade. São Paulo: Companhia Editora Nacional, pp.3546.

FONSECA, L., 1972. Comunicação de Inovações no Processo de Mudança. Brasilia, Universidade de Brasilia. 190p. il. 
FONSECA, L., 1973. Promoção Humana e Extensão Rural. In: PASTORE, J. Agricultura e Desenvolvimento. Rio de Jane $\underline{\mathbf{i}}$ ro, APEC. p.240-250.

HYMAN, H.H., 1955. Survey Design and Analysis: Principles, Cases, and Procedures. Glenco, I11., Free Press.

KAPLAN, A., 1969. A Conduta na Pesquisa. São Paulo, Editora Herder.

LOPES, R.S., 1966. Information Seeking Behavior of Country Extension Agents in Minas Gerais, Brazil. (s.1.). University of Wisconsin. 149p. il. (Tese Mestrado).

LOPES, R.S., 1976. O Modelo. Brasileiro de Extensão Rural. In: REUNIÃO ANUAL DA ASSOCIAÇÃO BRASILEIRA DE EDUCAÇÃO AGRICOLA SUPERIOR (ABEAS), 16., Piracicaba (SP), pp . 8-15.

MACHADO FILHO, F., 1973. Comunication Behavior of Texas Country Agricultural Agents. Austin, University of Texas, 133p. il. (Tese Mestrado).

MATA, V.S., 1978. Um Estudo Sobre as Atitudes do Extensionista Rural Frente ao Comportamento do Agricultor. Brasí 1ia, Universidade de Brasilia; 113p. il. (Tese Mestrado).

MERTON, R.K., 1968. Sociologia: Teoria e Estrutura. São Paulo. Mestre Jou. 758 .

O'MUIRCHEARTAIGH, C.A. \& C. PAYNE. ed., 1979. Exploring Data Structures. New York, John Wiley e sons.

PARSONS, T., 1974. O Sistema das Sociedades Modernas. Trad. Dante M. Leite. São Paulo, Pioneira. $192 \mathrm{p}$. 
PINTO, J.B., 1972. Extensión Agricola o Educación: una Disyuntiva Critica. Lima, Universidad Central de Venezuela, s.d. 64p. Trabalho apresentado no I Seminärio Nacional de Professores de Extensión Agricola a Nivel Universitario, s.1. 1972 .

RAMOS, A. de A., 1973. Comportamento dos Técnicos Responsâa veis Pelas Casas da Agricultura do Estado de São Paulo, Quanto à Busca de Informação. Viçosa, Universidade Fede ral de Viçosa, 1973. 181p. il. (Tese Mestrado).

SIMON, J.L., 1969. Basic Research Methods in Social Science. New York, Random House.

WARWICK, D.P. \& C.A. LININGER, 1975. The Sample Survey: Theory and Practice. New York, McGraw-Hill Book Co. 